\title{
Vertical profiles of the 3-D wind velocity retrieved from multiple wind lidars performing triple range-height-indicator scans
}

\author{
Mithu Debnath ${ }^{1}$, G. Valerio Iungo ${ }^{1}$, Ryan Ashton ${ }^{1}$, W. Alan Brewer ${ }^{2}$, Aditya Choukulkar $^{2}$, Ruben Delgado ${ }^{3}$, \\ Julie K. Lundquist ${ }^{4,5}$, William J. Shaw ${ }^{6}$, James M. Wilczak ${ }^{2}$, and Daniel Wolfe ${ }^{7}$ \\ ${ }^{1}$ Wind Fluids and Experiments (WindFluX) Laboratory, Mechanical Engineering Department, \\ The University of Texas at Dallas, Richardson, TX, USA \\ ${ }^{2}$ National Oceanic and Atmospheric Administration, Earth Sciences Research Laboratory, Boulder, CO, USA \\ ${ }^{3}$ Atmospheric Physics Department, University of Maryland Baltimore County, Baltimore, MD, USA \\ ${ }^{4}$ National Renewable Energy Laboratory, Golden, CO, USA \\ ${ }^{5}$ Department of Atmospheric and Oceanic Sciences, University of Colorado at Boulder, Boulder, CO, USA \\ ${ }^{6}$ Pacific Northwest National Laboratory, Richland, WA, USA \\ ${ }^{7}$ Physical Sciences Division, National Oceanic and Atmospheric Administration, Boulder, CO, USA
}

Correspondence to: G. V. Iungo (valerio.iungo@utdallas.edu)

Received: 13 May 2016 - Published in Atmos. Meas. Tech. Discuss.: 23 June 2016

Revised: 9 October 2016 - Accepted: 10 January 2017 - Published: 6 February 2017

\begin{abstract}
Vertical profiles of 3-D wind velocity are retrieved from triple range-height-indicator (RHI) scans performed with multiple simultaneous scanning Doppler wind lidars. This test is part of the eXperimental Planetary boundary layer Instrumentation Assessment (XPIA) campaign carried out at the Boulder Atmospheric Observatory. The three wind velocity components are retrieved and then compared with the data acquired through various profiling wind lidars and highfrequency wind data obtained from sonic anemometers installed on a $300 \mathrm{~m}$ meteorological tower. The results show that the magnitude of the horizontal wind velocity and the wind direction obtained from the triple RHI scans are generally retrieved with good accuracy. However, poor accuracy is obtained for the evaluation of the vertical velocity, which is mainly due to its typically smaller magnitude and to the error propagation connected with the data retrieval procedure and accuracy in the experimental setup.
\end{abstract}

\section{Introduction}

Wind Light Detection and Ranging (lidar) systems have been employed for wind velocity measurements in different disciplines, such as meteorology (Banta et al., 2002; Calhoun et al., 2006; Emeis et al., 2007; Horanyi et al., 2015; Vander- wende et al., 2015; Bonin et al., 2015), aeronautic transportation (George and Yang, 2012; Smalikho and Banakh, 2015), wind engineering (Jakobsen et al., 2015) and wind energy (Aitken et al., 2012, 2014; Iungo et al., 2013a; Iungo and Porté-Agel, 2014; Banta et al., 2015; Iungo, 2016). Specifically for wind energy, wind lidars are widely used for characterization of the atmospheric boundary layer (ABL) thanks to their relatively easy deployment, non-intrusiveness, and lower deployment and maintenance costs than for traditional met towers (Barthelmie et al., 2010; Schepers et al., 2012).

A Doppler wind lidar allows probing the atmospheric wind field by means of a light beam, which is backscattered in the atmosphere due to the presence of aerosol. The velocity component along the light beam direction, denoted as radial or line-of-sight (los) velocity, is evaluated from the Doppler shift of the backscattered light. Different scanning strategies can be designed to characterize different properties of the ABL velocity field (Sathe and Mann, 2013; Iungo and Porté-Agel, 2013b; Banta et al., 2015). The highest spectral resolution of the wind lidar measurements is achievable by maximizing the sampling frequency of the lidar and measuring over a fixed direction (Iungo et al., 2013a). Three-dimensional fixed-point measurements can be performed by retrieving the radial velocity measured simultaneously by three or more lidars intersecting at a fixed position 


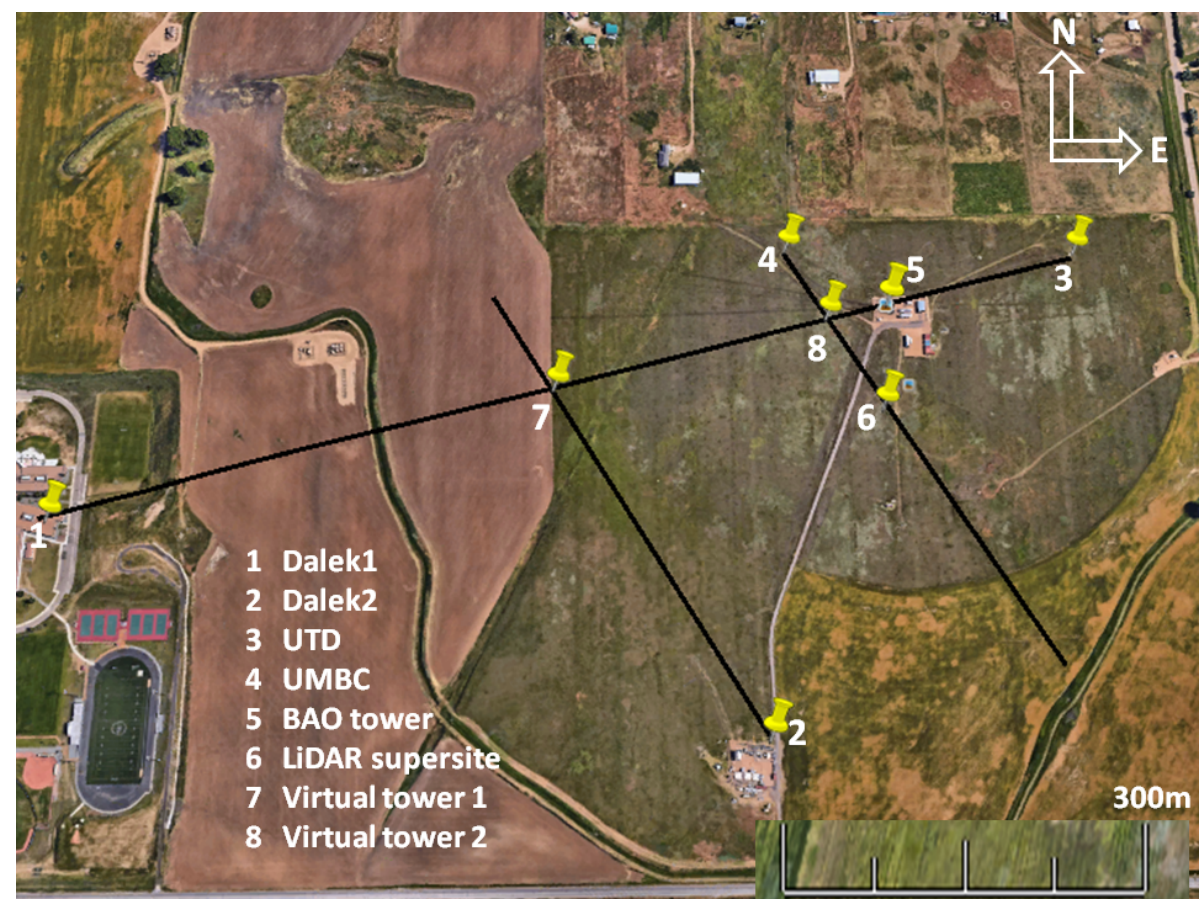

Figure 1. Map of the setup for the triple RHI scans performed during the XPIA experiment at BAO. Locations of the four scanning Doppler wind lidars, the two virtual towers, wind lidar profilers (lidar supersite) and BAO tower are reported.

(Mikkelsen et al., 2008; Mann et al., 2009; Carbajo-Fuertes et al., 2014; Berg et al., 2015).

Vertical profiles of the 3-D wind velocity within the ABL can be obtained by scanning the lidar laser beam over a conical path or through the Doppler beam swinging (DBS) technique (Courtney et al., 2008; Smalikho et al., 2013). These scanning techniques can be leveraged for the characterization of the incoming wind of a utility-scale wind turbine (Aitken et al., 2012). However, they are based on the assumption of a uniform wind field over horizontal planes within the measurement volume. Therefore, a significant error can be encountered for very heterogeneous flows, such as for wind turbine wakes (Lundquist et al., 2015) or ABL flows over complex terrain (Bingöl et al., 2009).

Details about the morphology connected with ABL flows can be achieved by sweeping the elevation angle of the lidar while keeping the azimuthal angle fixed, i.e., performing the range-height-indicator (RHI) scan (Käsler et al., 2010; Hill et al., 2010). The wind velocity field over a volume including the rotor disc of a utility-scale wind turbine can be measured with intersecting RHI scans and dual-Doppler lidar retrieval (Newsom et al., 2015). The velocity field of a wind turbine wake can be characterized over a vertical plane through RHI scans, although the continuous adjustment of the turbine yaw angle complicates the detection of the relative position between the wake and the measurement plane (Iungo et al., 2013a; Iungo and Porté-Agel, 2013b; Aitken et al., 2014).
Plan position indicator (PPI) scans are performed by varying the azimuthal angle of the lidar laser beam while keeping the elevation angle fixed, thus probing a conical surface. PPI scans are highly suitable for detection and characterization of wind turbine wakes for different wind directions, wake dynamics and meandering (Iungo et al., 2013a; Aitken et al., 2014; Banta et al., 2015). A series of consecutive PPI and RHI scans produces a volumetric scan (Banta et al., 2013; Iungo and Porté-Agel, 2014; Banta et al., 2015; Machefaux et al., 2015), which may be useful for a 3-D characterization of the radial velocity within wind turbine wakes.

For this study, four scanning Doppler wind lidars were programmed in order to perform simultaneous RHI scans. Various measurement planes are selected in order to determine specific locations for which two lidars perform coplanar RHI scans, while a third lidar measures over a plane roughly perpendicular to the one probed by the other two lidars (Fig. 1). With this measurement procedure, at the intersection location of the three lidar measurement planes, a vertical profile of the 3-D velocity wind field is retrieved, producing the so-called virtual tower scanning technique. Virtual towers were produced at two separate locations during the experiment.

Co-planar and triple RHI scans are highly compelling measurement strategies when investigating flows with a prevailing mean wind direction, such as for wind turbine wakes, or vorticity structures and eddies evolving with a specific direction. Co-planar RHI scans were performed to character- 
ize the vortical motion of eddies generated during mountainwave events (Hill et al., 2010). In Cherukuru et al. (2015), co-planar RHI scans were performed to investigate downslope-windstorm-type flows over a plane aligned with the slope of a crater. Co-planar RHI scans were also performed to investigate the wind field over the vertical symmetry plane of a wind turbine wake (Iungo et al., 2013a). In that paper, turbulent statistics of the streamwise and vertical velocities were obtained, together with the corresponding momentum flux. These measurements are highly valuable for wind turbine wake modeling and tuning of turbulence closure models. For this kind of applications, co-planar and triple RHI scans allow obtaining multiple measurement points over the vertical plane of interest by using the different range gates of the pulsed lidars and thus achieving small sampling periods. Furthermore, the third lidar enables the retrieval of the three velocity components as a vertical profile at the intersection line among the three RHI planes. Performing these measurements as consecutive triple fixed-point measurements, i.e., with three lidars set up with a generic arrangement, would lead to extremely long, and thus unfeasible, sampling periods. For the first time, at least to the authors' knowledge, the multiple-RHI-scan strategy is assessed against other measurement techniques, such as sonic anemometers and wind lidar profilers.

Accuracy of the triple-Doppler lidar retrieval from simultaneous intersecting RHI scans is then assessed by comparing the retrieved wind velocity data with the measurements acquired with two profiling wind lidars and sonic anemometers installed on a $300 \mathrm{~m}$ met tower located in proximity of the virtual tower locations (Mikkelsen et al., 2008; Mann et al., 2009; Carbajo-Fuertes et al., 2014).

The remainder of the paper is organized as follows: a description of the instruments used in the experiment is provided in Sect. 2. The data retrieval of the 3-D velocity from triple RHI scans is described in Sect. 3, together with the error analysis performed through comparisons with data collected from the lidar profilers and sonic anemometers. Concluding remarks are then reported in Sect. 4.

\section{Experimental setup and measurement procedures}

The eXperimental Planetary boundary layer Instrument Assessment (XPIA) field study was funded by the US Department of Energy within the Atmosphere to Electrons (A2e) program to estimate the accuracy and capabilities of various remote-sensing techniques for the characterization of complex atmospheric flows in and near wind farms. The XPIA experiment was carried out at the National Oceanic and Atmospheric Administration's (NOAA) Boulder Atmospheric Observatory (BAO) near Erie, Colorado, for the period 2 March-31 May 2015.

The field deployment comprised sonic anemometers installed over the BAO met tower, profiling lidars, radiosonde launches, microwave radiometers and two scanning Ka-band radars. Moreover, five scanning Doppler wind lidars were deployed to explore novel scanning strategies for the characterization of ABL flows. The triple RHI scan, which is the focus of this paper, is one of the tested scanning strategies. More details about the XPIA campaign can be found in Lundquist et al. (2016b).

The BAO met tower was built in 1977 to investigate the planetary boundary layer (Kaimal and Gaynor, 1983). This $300 \mathrm{~m}$ tall tower has three legs spaced $3 \mathrm{~m}$ apart, and it is instrumented with temperature and relative humidity sensors at 10, 100 and $300 \mathrm{~m}$ above ground level (a.g.1.), while 12 CSAT3 3-D sonic anemometers by Campbell Scientific were installed at 50, 100, 150, 200, 250 and $300 \mathrm{~m}$ a.g.l. Six anemometers were installed on booms pointing $\mathrm{NW}\left(334^{\circ}\right)$, which are denoted as NW sonic anemometers, while the other six anemometers were installed on SE booms $\left(154^{\circ}\right)$, denoted as SE sonic anemometers. Most of the booms were $4.3 \mathrm{~m}$ long, while at the $250 \mathrm{~m}$ level the SE boom was $3.3 \mathrm{~m}$ long. Sonic anemometers data, which were acquired with a sampling frequency of $20 \mathrm{~Hz}$, were tilt-corrected following the method proposed in Wilczak et al. (2001). The sonic anemometers were calibrated for the XPIA experiment by the sonic manufacturing company Campbell Scientific, with measurement resolution (maximum offset error) of $0.1 \mathrm{~cm} \mathrm{~s}^{-1}\left(8 \mathrm{~cm} \mathrm{~s}^{-1}\right)$ for the horizontal velocity and $0.05 \mathrm{~cm} \mathrm{~s}^{-1}\left(4 \mathrm{~cm} \mathrm{~s}^{-1}\right)$ for the vertical velocity (McCaffrey et al., 2016).

Two Leosphere/NRG Windcube v1 profiling lidars (denoted as V1) were deployed by the University of Colorado Boulder and NCAR's Research Applications Laboratory during XPIA (Aitken et al., 2012; Rhodes and Lundquist, 2013). Three-dimensional vertical profiles of the wind velocity were carried out with the DBS technique with an elevation angle from vertical of $28^{\circ}$, and range gates were centered from $40 \mathrm{~m}$ to $220 \mathrm{~m}$ a.g.l. with steps of $20 \mathrm{~m}$. Similar scans were performed with one Leosphere Windcube offshore 8.66 profiling lidar, which is denoted as V2. The V2 lidar acquired data at 11 vertical heights $(40,50,60,80,100,120,140$, $150,160,180$ and $200 \mathrm{~m}$ ). The sampling frequency for the lidar profilers was about $1 \mathrm{~Hz}$. All the lidar profilers were deployed at the location referred to as lidar supersite and reported in Fig. 1. Its GPS coordinates are reported in Table 1 . The profiling lidar data were assessed against sonic anemometer data during XPIA, showing a very good agreement with mean difference of $-0.03 \mathrm{~m} \mathrm{~s}^{-1}$ and $R^{2}$ of 0.97 (Lundquist et al., 2016b). The slightly lower correlation between sonic anemometers and lidar profilers might be due to the separation distance between the met tower and the location of the lidar profilers (Table 2).

Four scanning Doppler wind lidars were deployed for this experiment. The setup comprises four Leosphere Windcube 200S (University of Texas at Dallas (UTD), NOAA Dalek1, NOAA Dalek2 and University of Maryland Baltimore County (UMBC)). Wind measurements were per- 
Table 1. GPS locations of the four scanning Doppler wind lidars, two virtual towers generated with the triple RHI scans, wind lidar profilers (lidar supersite) and BAO tower.

\begin{tabular}{lllr}
\hline & Longitude & Latitude & Elevation \\
\hline UTD & $105^{\circ} 0^{\prime} 3.99^{\prime \prime} \mathrm{W}$ & $40^{\circ} 03^{\prime} 02.32^{\prime \prime} \mathrm{N}$ & $1578 \mathrm{~m}$ \\
Dalek1 & $105^{\circ} 0^{\prime} 55.64^{\prime \prime} \mathrm{W}$ & $40^{\circ} 02^{\prime} 51.75^{\prime \prime} \mathrm{N}$ & $1578 \mathrm{~m}$ \\
Dalek2 & $105^{\circ} 0^{\prime} 20.65^{\prime \prime} \mathrm{W}$ & $40^{\circ} 02^{\prime} 43.09^{\prime \prime} \mathrm{N}$ & $1585 \mathrm{~m}$ \\
$\mathrm{UMBC}$ & $105^{\circ} 0^{\prime} 18.90^{\prime \prime} \mathrm{W}$ & $40^{\circ} 03^{\prime} 02.56^{\prime \prime} \mathrm{N}$ & $1577 \mathrm{~m}$ \\
Virtual tower 1 & $105^{\circ} 0^{\prime} 30.82^{\prime \prime} \mathrm{W}$ & $40^{\circ} 02^{\prime} 56.73^{\prime \prime} \mathrm{N}$ & $1578 \mathrm{~m}$ \\
Virtual tower 2 & $105^{\circ} 0^{\prime} 16.77^{\prime \prime} \mathrm{W}$ & $40^{\circ} 02^{\prime} 59.58^{\prime \prime} \mathrm{N}$ & $1578 \mathrm{~m}$ \\
BAO tower & $105^{\circ} 0^{\prime} 13.82^{\prime \prime} \mathrm{W}$ & $40^{\circ} 03^{\prime} 00.13^{\prime \prime} \mathrm{N}$ & $1579 \mathrm{~m}$ \\
Lidar supersite & $105^{\circ} 0^{\prime} 14.36^{\prime \prime} \mathrm{W}$ & $40^{\circ} 02^{\prime} 55.72^{\prime \prime} \mathrm{N}$ & $1580 \mathrm{~m}$ \\
\hline
\end{tabular}

Table 2. Distance of the four scanning Doppler wind lidars from their respective virtual towers.

\begin{tabular}{lrr}
\hline & Virtual tower & Virtual tower \\
& $1(\mathrm{~m})$ & $2(\mathrm{~m})$ \\
\hline UTD & 647 & 314 \\
Dalek1 & 626 & 955 \\
Dalek2 & 480 & - \\
UMBC & - & 98 \\
BAO tower & 415 & 71 \\
Lidar supersite & 393 & 136 \\
\hline
\end{tabular}

formed by means of an eye-safe laser with a pulse energy of $0.1 \mathrm{~mJ}$ and wavelength of $1.54 \mu \mathrm{m}$. Measurements were acquired by using an accumulation time of $0.5 \mathrm{~s}$ and gate length of $50 \mathrm{~m}$. Locations of the four scanning Doppler wind lidars are shown in Fig. 1, while their GPS positions are reported in Table 1. Accuracy in the radial velocity of each scanning lidar is always smaller than $0.5 \mathrm{~m} \mathrm{~s}^{-1}$, while the angular resolution of the scanning head is smaller than $0.01^{\circ}$. Accuracy in the laser pointing was evaluated through hard-target tests by pointing the lidars against the met tower. These experiments allowed estimating the bias errors in azimuthal and elevation angles. The actual pointing accuracy was estimated to be less than $0.1^{\circ}$, while repeatability, which was estimated through consecutive clockwise and counterclockwise scans, was estimated to be $0.01^{\circ}$ for the azimuthal angle and $0.05^{\circ}$ for the elevation angle.

During the XPIA experiment, 12 scanning strategies were tested, and the triple RHI scan was performed for approximately 1 day. However, the poor local aerosol conditions occurring in early spring led to a relatively low carrier-tonoise ratio of the lidar velocity signals and thus to limited data availability. Although this dataset represents the first assessment of the scanning strategy under examination, the relatively short sampling period (03:00-05:00 UTC on 21 April 2015) of this experiment does not allow estimating effects of wind and atmospheric conditions on the accuracy of the triple RHI technique.
All the lidars used an accumulation time of $500 \mathrm{~ms}$ for each line-of-sight position, with a range gate of $50 \mathrm{~m}$ but $25 \mathrm{~m}$ for the UMBC lidar (see Table 3). Ranges of the elevation angles for the RHI scans of the various lidars were selected in order to cover heights between $50 \mathrm{~m}$ and $320 \mathrm{~m}$ a.g.l. for virtual tower 1 , and between 20 and $90 \mathrm{~m}$ for virtual tower 2. For each height of the virtual tower and each lidar, the closest range gate to the considered measurement point is selected for the data retrieval. The maximum horizontal distance of a gate centroid from the respective tower measurement point is $25 \mathrm{~m}$, while the vertical one is always smaller than $10 \mathrm{~m}$. No spatial interpolation of the lidar data was carried out for the data retrieval of the triple RHI scan. Details of the setup for the RHI scans are reported in Table 3. The UTD lidar measured with an azimuthal angle of $\theta=71.93^{\circ}$ from north, Dalek1 with $\theta=251.93^{\circ}$, UMBC lidar with $\theta=332^{\circ}$ and Dalek2 with $\theta=154^{\circ}$.

Intersections of the various RHI measurement planes determine two virtual towers, whose GPS coordinates are reported in Table 1. Distances of the lidars from the virtual tower locations are reported in Table 2.

For virtual tower 1, the UTD lidar covered the measurement range with an average time period of $13 \mathrm{~s}$, while on average $20 \mathrm{~s}$ was required to cover the remaining higher heights and restart a consecutive scan in raster mode, i.e., in the opposite direction than the previous one. Similarly, Dalek1 required an average period of $13 \mathrm{~s}$ to measure the vertical profile over virtual tower 1 and $19.5 \mathrm{~s}$ to restart the next scan. Dalek 2 required on average $18 \mathrm{~s}$ to measure the vertical profile and $37 \mathrm{~s}$ to restart the next scan. A longer period between consecutive scans was required for Dalek2 due to the scan schedule involving other measurements. Moreover, Dalek2 periodically performed PPI scans with an average scan period of $6 \mathrm{~min}$ and intervals between consecutive PPI scans of $12 \mathrm{~min}$. Analogous data for virtual tower 2 are reported in Table 4 . Three-dimensional velocity profiles at the virtual tower locations were retrieved for time periods for which the three respective RHI scans overlap.

The lidars were not synchronized; thus different time periods of overlapping were obtained due to the different delays of the lidar systems. The overlapping period is defined as the amount of time for which all the three lidars scanned simultaneously over the height of the virtual tower under examination. Histograms of the overlapping period for the two virtual towers are reported in Fig. 2. For virtual tower 1, the overlapping time is generally smaller than $2 \mathrm{~s}$, while for virtual tower 2 all three lidars scanned continuously over the height range, and the overlapping time has an upper bound limited by the sampling period of Dalek1, which is equal to $3.5 \mathrm{~s}$. The collected lidar data are further post-processed only if the carrier-to-noise ratio of the lidar data is larger than $-17 \mathrm{~dB}$ (Carbajo-Fuertes et al., 2014). 
Table 3. Parameters of the different scanning lidars for the triple RHI scans.

\begin{tabular}{lrrrr}
\hline & $\begin{array}{r}\text { Azimuthal } \\
\text { angle }\left(^{\circ}\right)\end{array}$ & $\begin{array}{r}\text { Elevation angle } \\
\text { range }\left(^{\circ}\right)\end{array}$ & $\begin{array}{r}\text { Angular resolution } \\
\left({ }^{\circ}\right)\end{array}$ & $\begin{array}{r}\text { Gate length } \\
(\mathrm{m})\end{array}$ \\
\hline UTD & 71.93 & $0-45$ & 1 & 50 \\
Dalek1 & 251.93 & $0-45$ & 1 & 50 \\
Dalek2 & 154 and 244 & $0-45$ & 1 & 50 \\
UMBC & 332 & $0-45$ & 1 & 25 \\
\hline
\end{tabular}

Table 4. Average sampling period, $t_{\mathrm{S}}$, and time interval between consecutive scans, $t_{\mathrm{r}}$, for the various lidars performing the different virtual towers.

\begin{tabular}{lrrrrr}
\hline & \multicolumn{2}{c}{ Virtual tower 1} & & \multicolumn{2}{c}{ Virtual tower 2} \\
\cline { 2 - 3 } \cline { 5 - 6 } & $t_{\mathrm{s}}(\mathrm{s})$ & $t_{\mathrm{r}}(\mathrm{s})$ & & $t_{\mathrm{s}}(\mathrm{s})$ & $t_{\mathrm{r}}(\mathrm{s})$ \\
\hline UTD & 13 & 19 & & 6 & 28 \\
Dalek1 & 13 & 19.5 & & 3.5 & 38 \\
Dalek2 & 18 & 37 & & - & - \\
UMBC & - & - & & 21 & 4 \\
\hline
\end{tabular}

\section{Retrieval and assessment of 3-D wind velocity from triple RHI scans}

Data retrieval is described in detail for virtual tower 1; similar procedures apply to virtual tower 2 . For virtual tower 1 , the UTD lidar and Dalek1 performed RHI scans over the same vertical plane but with a difference of $180^{\circ}$ for the azimuthal angle of their scanning heads (see Fig. 1). Therefore, when the two lidars are set with the same elevation angle, at a given location they will measure a radial velocity with the same magnitude and opposite sign. Simultaneously, Dalek2 performed RHI scans over a plane roughly orthogonal to the one probed by the other two lidars (Dalek1 and UTD). Specifically, the measurement plane of Dalek2 is shifted by an azimuthal angle $\Delta \theta=-7.93^{\circ}$ (positive is a clockwise shift towards higher azimuthal angles) with respect to the orthogonal plane, while $\Delta \theta=-9.93^{\circ}$ for virtual tower 2 .

Three orthogonal velocity components are retrieved, namely the in-plane horizontal velocity, $U_{\text {in }}$, which lies on the measurement plane of the UTD lidar and Dalek1; the horizontal transversal velocity, $U_{\text {tr }}$, which is orthogonal to $U_{\text {in }}$; and the vertical velocity, $W$. These three velocity components can be evaluated from the radial velocities of the three lidars as follows:

$$
\begin{aligned}
{\left[\begin{array}{c}
U_{\mathrm{in}} \\
U_{\mathrm{tr}} \\
W
\end{array}\right] } & =\left[\begin{array}{ccc}
\cos \left(\phi_{\mathrm{UTD}}\right) & 0 & \sin \left(\phi_{\mathrm{UTD}}\right) \\
\sin (\Delta \theta) \cos \left(\phi_{\mathrm{D} 2}\right) & \cos (\Delta \theta) \cos \left(\phi_{\mathrm{D} 2}\right) & \sin \left(\phi_{\mathrm{D} 2}\right) \\
-\cos \left(\phi_{\mathrm{D} 1}\right) & 0 & \sin \left(\phi_{\mathrm{D} 1}\right)
\end{array}\right]^{-1} \\
& \times\left[\begin{array}{c}
U_{\mathrm{r}}^{\mathrm{UTD}} \\
U_{\mathrm{r}}^{\mathrm{D} 2} \\
U_{\mathrm{r}}^{\mathrm{D} 1}
\end{array}\right]
\end{aligned}
$$

where $\phi$ and $U_{\mathrm{r}}$ represent elevation angle and radial velocity of the various lidars, respectively. From Eq. (1), the three
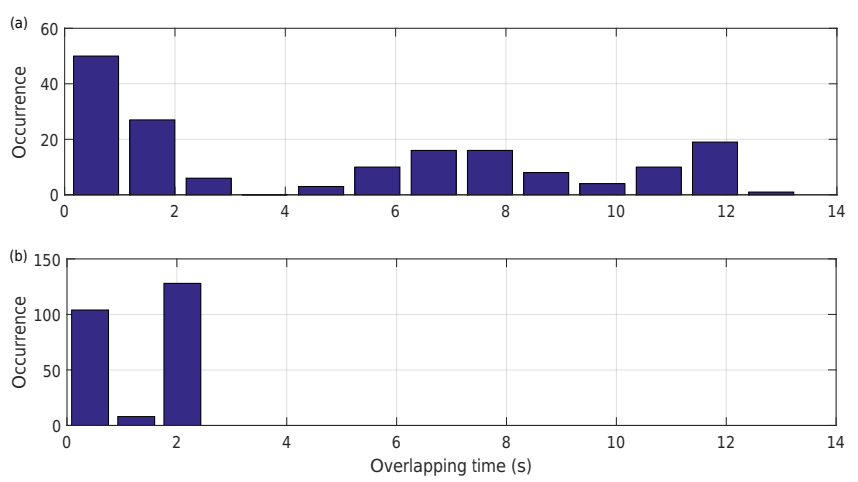

Figure 2. Histograms of the overlapping time between the different lidars for the virtual towers: (a) virtual tower 1; (b) virtual tower 2.

orthogonal velocities can be retrieved directly from the three radial velocities as follows:

$$
\begin{aligned}
& U_{\text {in }}=\frac{\sin \left(\phi_{\mathrm{D} 1}\right) U_{\mathrm{r}}^{\mathrm{UTD}}-\sin \left(\phi_{\mathrm{UTD}}\right) U_{\mathrm{r}}^{\mathrm{D} 1}}{\cos \left(\phi_{\mathrm{UTD}}\right) \sin \left(\phi_{\mathrm{D} 1}\right)+\sin \left(\phi_{\mathrm{UTD}}\right) \cos \left(\phi_{\mathrm{D} 1}\right)} \\
& U_{\mathrm{tr}}=\frac{U_{\mathrm{r}}^{\mathrm{D} 2}}{\cos \left(\phi_{\mathrm{D} 2}\right) \cos (\Delta \theta)} \\
& \begin{array}{l}
\cos \left(\phi_{\mathrm{D} 2}\right) \cos (\Delta \theta) \\
U_{\mathrm{r}}^{\mathrm{UTD}}\left[\cos \left(\phi_{\mathrm{D} 1}\right) \sin \left(\phi_{\mathrm{D} 2}\right)+\cos \left(\phi_{\mathrm{D} 2}\right) \sin \left(\phi_{\mathrm{D} 1}\right) \sin (\Delta \theta)\right]
\end{array} \\
& -\frac{\mathrm{r}}{\cos \left(\phi_{\mathrm{D} 2}\right) \cos (\Delta \theta)\left[\cos \left(\phi_{\mathrm{UTD}}\right) \sin \left(\phi_{\mathrm{D} 1}\right)+\sin \left(\phi_{\mathrm{UTD}}\right) \cos \left(\phi_{\mathrm{D} 1}\right)\right]} \text {. } \\
& U_{\mathrm{r}}^{\mathrm{D} 1}\left[\cos \left(\phi_{\mathrm{UTD}}\right) \sin \left(\phi_{\mathrm{D} 2}\right)+\cos \left(\phi_{\mathrm{D} 2}\right) \sin \left(\phi_{\mathrm{UTD}}\right) \sin (\Delta \theta)\right] \\
& -\frac{\mathrm{T}}{\cos \left(\phi_{\mathrm{D} 2}\right) \cos (\Delta \theta)\left[\cos \left(\phi_{\mathrm{UTD}}\right) \sin \left(\phi_{\mathrm{D} 1}\right)+\sin \left(\phi_{\mathrm{UTD}}\right) \cos \left(\phi_{\mathrm{D} 1}\right)\right]} \\
& W=\frac{\cos \left(\phi_{\mathrm{D} 1}\right) U_{\mathrm{r}}^{\mathrm{UTD}}+\cos \left(\phi_{\mathrm{UTD}}\right) U_{\mathrm{r}}^{\mathrm{D} 1}}{\cos \left(\phi_{\mathrm{UTD}}\right) \sin \left(\phi_{\mathrm{D} 1}\right)+\sin \left(\phi_{\mathrm{UTD}}\right) \cos \left(\phi_{\mathrm{D} 1}\right)}
\end{aligned}
$$

The in-plane velocity, $U_{\text {in }}$, and the vertical velocity, $W$, are retrieved only from $U_{\mathrm{r}}^{\mathrm{UTD}}$ and $U_{\mathrm{r}}^{\mathrm{D} 1}$, and are not affected by the measurements carried out with the lidar Dalek2. However, the transversal velocity, $U_{\mathrm{tr}}$, is probed only by the lidar Dalek2, but the retrieval of $U_{\mathrm{tr}}$ is a function of the radial velocities measured by the three lidars.

Accuracy in sensing the 3-D velocity field with the tripleDoppler lidar technique is dependent on the setup of the three lidars and thus on the combination of their elevation and azimuthal angles. The three lines of sight should be set in order to be optimally sensitive to the three orthogonal wind velocity components (Carbajo-Fuertes et al., 2014). A quantification of the suitability of a triple-Doppler lidar setup for probing the 3-D wind velocity field is provided by the $L_{2}$-norm of the rows of the matrix reported in Eq. (1) (Simley et al., 2016). Divergence of the row norm from the value 1, both towards larger and smaller values, indicates an increased error in the retrieval of the respective wind velocity component. 


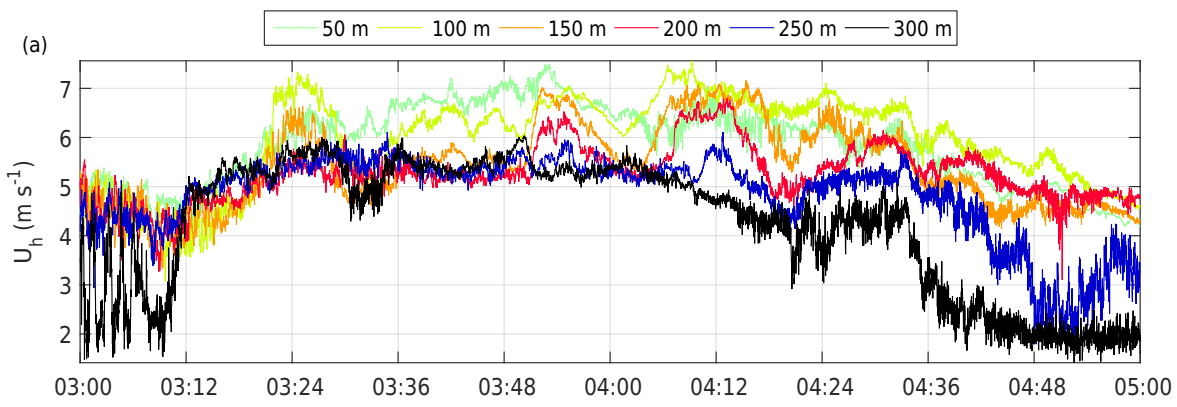

(b)

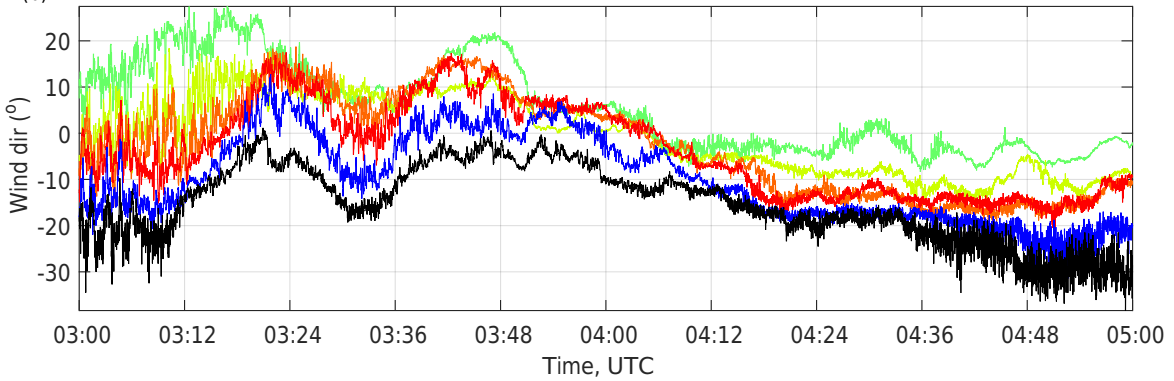

Figure 3. Wind velocity measurements obtained from the NW sonic anemometers installed on the met tower: (a) horizontal velocity; (b) wind direction. 21 April 2015, 03:00-05:00 UTC.

Table 5. Error analysis on the retrieval of the 3-D wind velocity from triple-Doppler lidar measurements as a function of the lidar setup for the various virtual towers and heights.

\begin{tabular}{lrrr}
\hline \multicolumn{4}{c}{ Virtual tower 1 } \\
\hline Height $(\mathrm{m})$ & $U_{\text {in }}$ & $U_{\text {tr }}$ & $W$ \\
\hline 60 & 0.7103 & 1.3949 & 7.5324 \\
80 & 0.7127 & 1.4015 & 5.6686 \\
100 & 0.7158 & 1.4101 & 4.5547 \\
120 & 0.7197 & 1.4205 & 3.8157 \\
140 & 0.7241 & 1.4327 & 3.2908 \\
160 & 0.7292 & 1.4466 & 2.8996 \\
180 & 0.7349 & 1.4621 & 2.5978 \\
200 & 0.7413 & 1.4794 & 2.3583 \\
250 & 0.7598 & 1.5292 & 1.9337 \\
300 & 0.7818 & 1.5884 & 1.6582 \\
\hline & Virtual tower 2 & \\
\hline Height $(\mathrm{m})$ & $U_{\text {in }}$ & $U_{\text {tr }}$ & $W$ \\
\hline 40 & 0.79345 & 3.7075 & 8.3921 \\
60 & 0.7950 & 3.7538 & 5.6258 \\
80 & 0.7972 & 3.8179 & 4.2518 \\
100 & 0.7999 & 3.8987 & 3.4345 \\
\hline
\end{tabular}

The error analysis related to the lidar setup used for the triple RHI scans is reported in Table 5 for the two virtual towers and heights. The error in the evaluation of the vertical velocity, $W$, decreases with increasing height of the virtual tower, which is mainly a consequence of the increased elevation an-
Table 6. Bias errors used for the triple-Doppler data retrieval.

\begin{tabular}{lrrrr}
\hline & $\begin{array}{r}\text { Scanner } \\
\text { height }(\mathrm{m})\end{array}$ & $\begin{array}{r}\text { Azimuth } \\
\left({ }^{\circ}\right)\end{array}$ & $\begin{array}{r}\text { Elevation } \\
\left({ }^{\circ}\right)\end{array}$ & $\begin{array}{r}\text { los velocity } \\
\left(\mathrm{m} \mathrm{s}^{-1}\right)\end{array}$ \\
\hline UTD & 1.37 & 4.93 & -0.89 & 0.6 \\
Dalek1 & 1.37 & 3.45 & 0.0 & 0.0 \\
Dalek2 & 1.37 & 7.70 & 0.0 & 0.0 \\
UMBC & 1.37 & -40.87 & -0.64 & -0.5 \\
\hline
\end{tabular}

gles of the lidars and thus of a larger projection of the lidar range gates in the vertical direction. For the two horizontal velocities, $U_{\text {in }}$ and $U_{\text {tr }}$, the setup is such to produce a very slowly increasing error for increased heights.

Various bias errors are considered for the data retrieval of the 3-D wind velocity. Corrections of the position of the lidar scanner heads, azimuth and elevation angles were estimated with hard-target experiments and GPS measurements, which are not detailed here for the sake of brevity (see Lundquist et al. (2016a) for details). Bias errors are reported in Table 6 for all the lidars, including bias errors in the radial velocity, which were estimated from fixed vertical velocity measurements performed over 1-day periods. Bias in the radial velocity was due to improper calibration of the acousto-optic modulator (AOM) frequency shift in the laser pulse, which was stable and reproducible in several tests independent of sonic anemometer comparison, and could simply be subtracted out of the lidar measurements.

Intercomparison of the 3-D wind velocity field retrieved from the triple RHI scans with the profiler wind lidars V1 


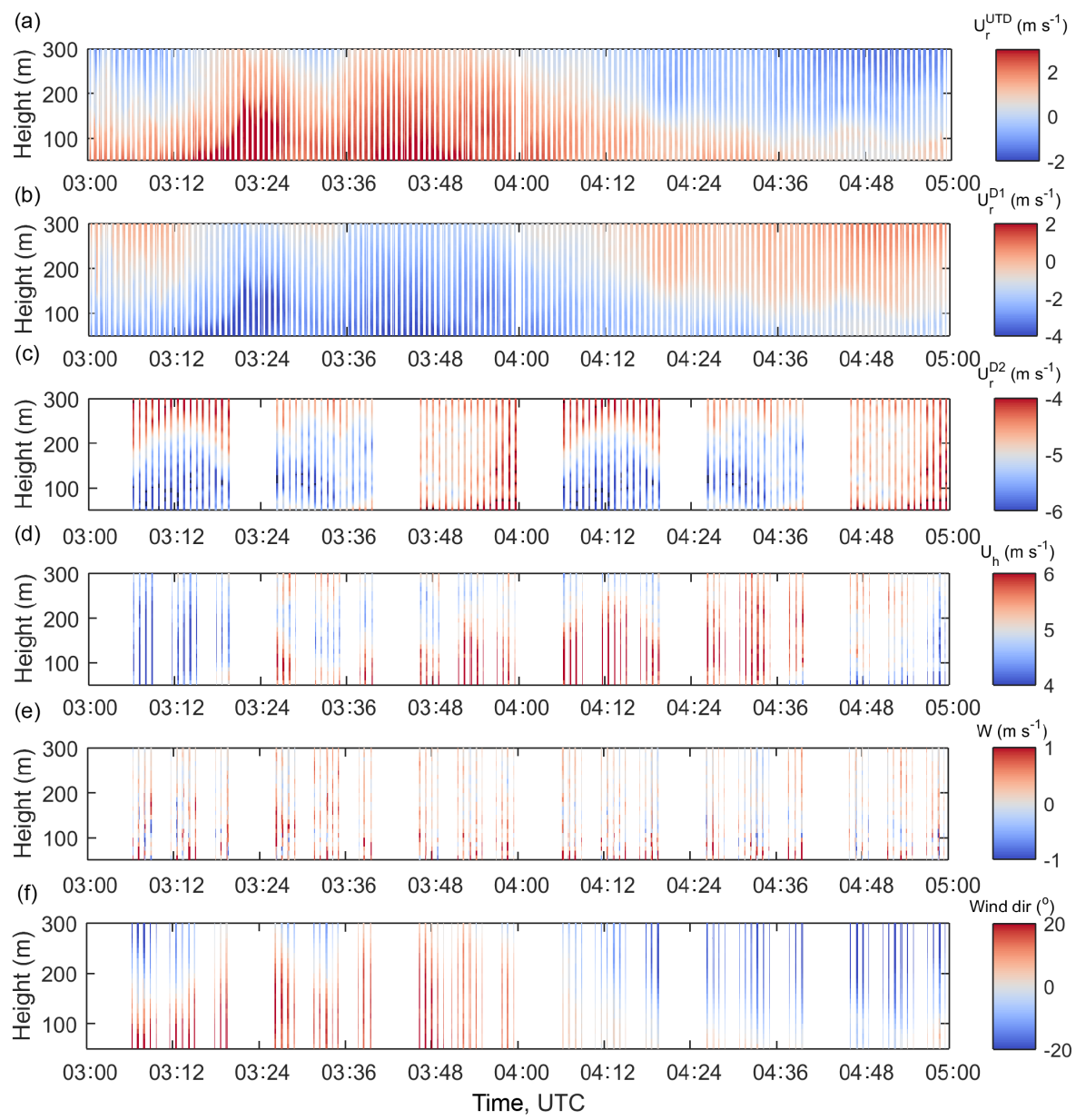

Figure 4. Wind velocity measurement for virtual tower 1: (a) UTD lidar radial velocity, $U_{\mathrm{r}}^{\mathrm{UTD}}$; (b) Dalek1 radial velocity, $U_{\mathrm{r}}^{\mathrm{D} 1}$; (c) Dalek2 radial velocity, $U_{\mathrm{r}}^{\mathrm{D} 2}$; (a) horizontal velocity, $U_{\mathrm{h}}$; (e) vertical velocity, $W$; (f) wind direction.

and $\mathrm{V} 2$, and the sonic anemometer data acquired from the BAO met tower is generally performed by down-sampling data with higher sampling frequency to the time stamps of the data with lower sampling frequency. For instance, the sonic anemometer data acquired with a sampling frequency of $20 \mathrm{~Hz}$ are interpolated to the time stamps of the triple RHI scans by averaging the sonic anemometer data over the corresponding time period of each lidar data. Similarly, the triple RHI data are interpolated on the 2 min averaged data obtained from the lidar profilers V1 and V2.

We note that the sonic anemometers can experience wake effects from the tower for specific wind directions, i.e., $111^{\circ} \leq \theta \leq 197^{\circ}$ for the NW anemometers and $299^{\circ} \leq$ $\theta \leq 20^{\circ}$ for the SE anemometers (Lundquist et al., 2016b; McCaffrey et al., 2016). For this experiment, wind direction varied between 330 and $20^{\circ}$, which indicates that the SE anemometers might be affected by wake effects. Horizontal velocity and wind direction measured by the NW sonic anemometers during the experiment are reported in Fig. 3. Wind speeds were generally low, with a maximum value over height of the time-averaged velocity of $5.9 \mathrm{~m} \mathrm{~s}^{-1}$ at about $100 \mathrm{~m}$ and average turbulence intensity of $5.6 \%$. The time-averaged Obukhov length estimated over the entire duration of the experiment from a sonic anemometer installed at a $5 \mathrm{~m}$ height was $4.6 \mathrm{~m}$, thus with a stability parameter of $z / L \approx 1.087$.

Figure 4 shows the collected radial velocities and retrieved wind velocity components for the period 03:00-05:00 UTC on 21 April 2015 at virtual tower 1. In Fig. 4a, b and c, the measured radial velocities show qualitatively the characteristic sampling period of the three lidars and time intervals between consecutive scans. For Dalek2, longer periods with no collected data are observed, which are connected with the time periods when PPI scans were performed.

A detailed assessment of the triple RHI scans with sonic anemometer and lidar profiler data is now presented for virtual tower 1 at a height of $100 \mathrm{~m}$. The radial velocities measured from the three lidars are reported in Fig. 5a. The inplane and vertical velocities are then retrieved from the radial velocities $U_{\mathrm{r}}^{\mathrm{UTD}}$ and $U_{\mathrm{r}}^{\mathrm{D} 1}$ as for Eq. (2). As shown in 

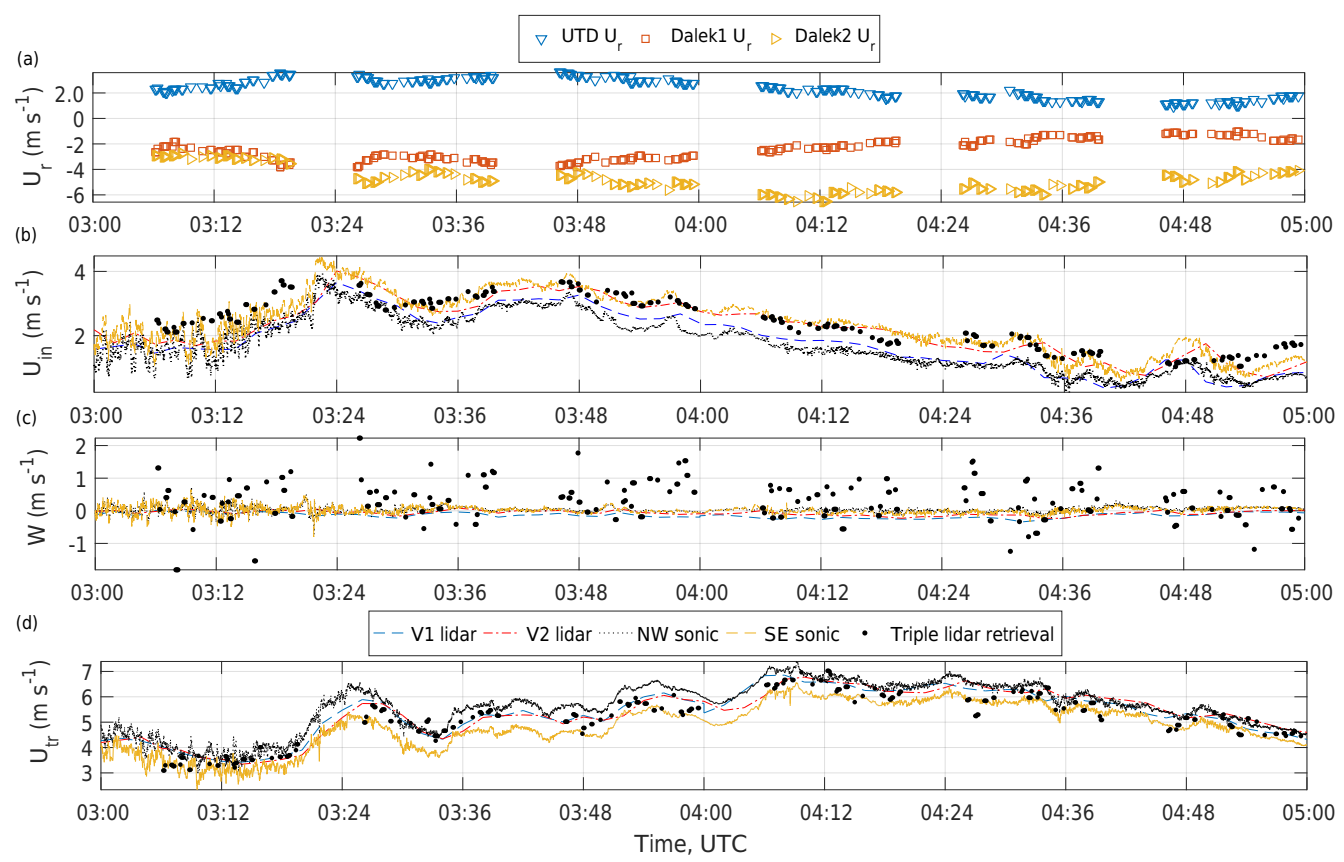

Figure 5. 3-D velocity retrieved for virtual tower 1 at $100 \mathrm{~m}$ height. Assessment of the triple RHI scans with sonic anemometer, and lidar profiler data: (a) radial velocities; (b) in-plane horizontal velocity, $U_{\text {in }}$; (c) vertical velocity, $W$; (d) transverse horizontal velocity, $U_{\text {tr }}$.

Table 7. Mean square value of the difference between velocities measured from different instruments.

\begin{tabular}{lrrc}
\hline Instruments & $U_{\text {in }}$ & $U_{\text {tr }}$ & $W$ \\
\hline V2 lidar - V1 lidar & 0.16 & 0.03 & 0.01 \\
V2 lidar - SE sonic & 0.03 & 0.20 & 0.02 \\
V2 lidar - NW sonic & 0.21 & 0.10 & 0.02 \\
V1 lidar - SE sonic & 0.18 & 0.28 & 0.04 \\
V1 lidar - NW sonic & 0.05 & 0.07 & 0.03 \\
SE sonic - NW sonic & 0.19 & 0.24 & 0.01 \\
V2 lidar - triple RHI & 0.09 & 0.15 & 0.25 \\
V1 lidar - triple RHI & 0.18 & 0.17 & 0.30 \\
NW sonic - triple RHI & 0.15 & 0.24 & 0.24 \\
SE sonic - triple RHI & 0.09 & 0.15 & 0.27 \\
\hline
\end{tabular}

Fig. $5 \mathrm{~b}, U_{\text {in }}$ estimated from the triple RHI scan is in good agreement with that obtained from the other measurement techniques. The mean square value of the difference for the velocities measured from different instruments is reported in Table 7. The estimated difference is the result of the accuracy of the wind lidars; the post-process procedure; the relatively short sampling time, which is consequent to the overlapping time of the different RHI scans (Fig. 2); and the distance between the locations of the virtual tower, lidar profilers and met tower (Table 2 and Fig. 1). The in-plane horizontal velocity, $U_{\text {in }}$, retrieved through the triple RHI scan is characterized by a similar level of accuracy to that measured from the other instruments.
A larger error is generally encountered for the retrieval of the vertical velocity, $W$ (Fig. 5c). This large difference in the measurement of the vertical velocity confirms the estimate of the retrieval error analysis reported in Table 7. Then, by injecting $U_{\text {in }}$ and $W$ in Eq. (2), the transversal velocity $U_{\text {tr }}$ is obtained. Figure $5 \mathrm{~d}$, shows that $U_{\text {tr }}$ retrieved from the triple RHI scans agrees generally well with the one obtained from the other instruments.

Accuracy in the evaluation of the 3-D wind velocity from triple RHI scans is assessed through linear regression with respective velocities evaluated from the NW and SE sonic anemometers, and the lidar profilers V1 and V2. Performing a linear regression between sonic anemometer and lidar profiler data, we obtained on average slope $=0.86$ and $R^{2}=0.94$ for $U_{\text {in }}$, slope $=0.85$ and $R^{2}=0.85$ for $U_{\text {tr }}$, and slope $=0.46$ and $R^{2}=0.35$ for $W$. From Fig. 6, it is already evident that the two horizontal velocity components, $U_{\text {in }}$ and $U_{\text {tr }}$, are retrieved with a good accuracy. However, accuracy in the estimate of the vertical velocity, $W$, is very poor. In Fig. 7, slopes and $R^{2}$ values of the linear regression are reported for the various instruments and velocity components. Accuracy in the estimate of the in-plane horizontal velocity, $U_{\text {in }}$, is generally good, with average slope of 1.01 and $R^{2}$ of 0.93. A lower agreement with the sonic anemometer data is observed for levels higher than $200 \mathrm{~m}$, which might be due to the larger fluctuations of the sonic data at higher levels. Regarding the horizontal transversal component, $U_{\text {tr }}$, a slightly lower accuracy is estimated, with an average slope of 0.88 

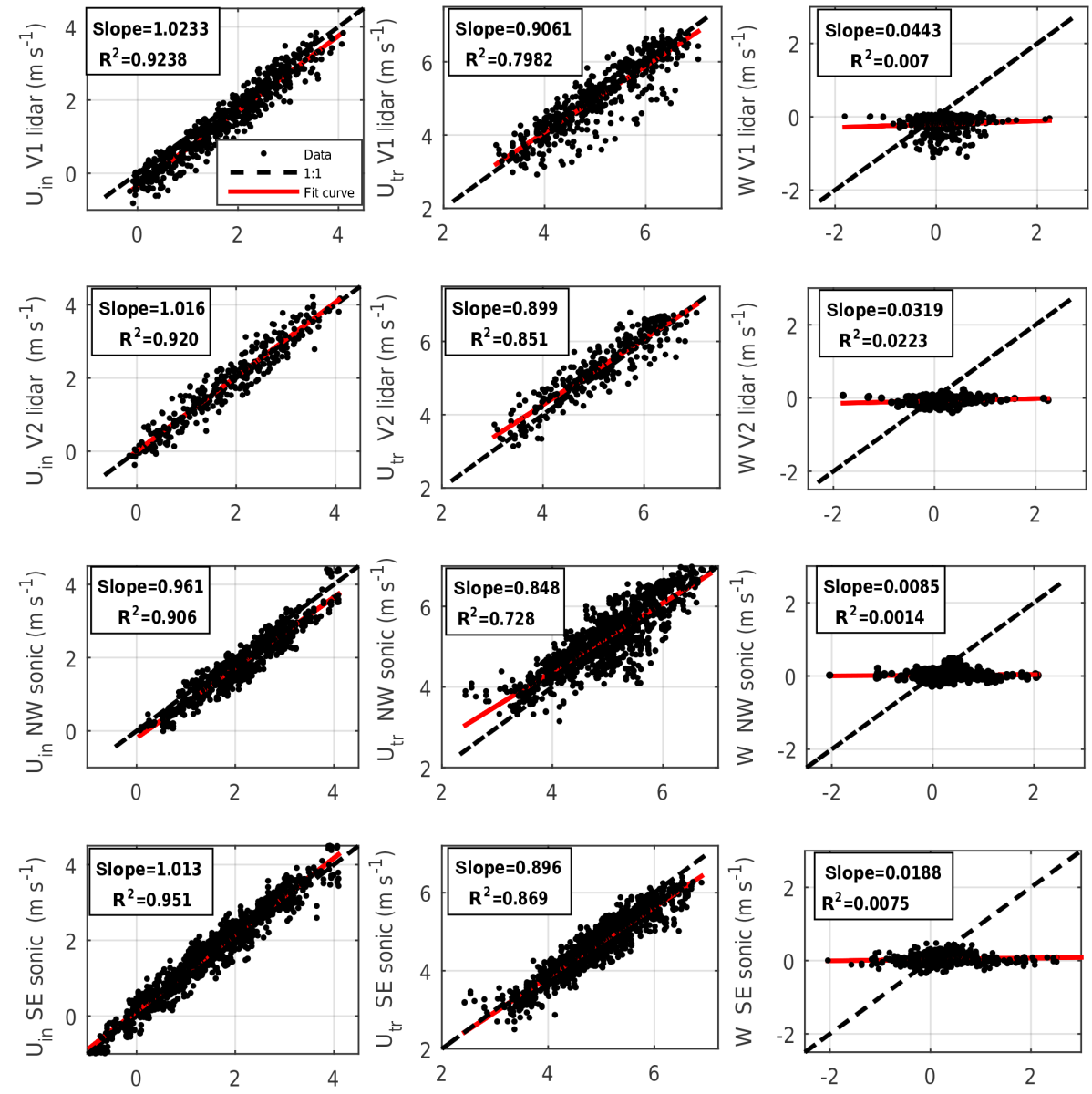

$\mathrm{U}_{\text {in }}$ Triple Doppler lidar $\left(\mathrm{m} \mathrm{s}^{-1}\right)$

$\mathrm{U}_{\mathrm{tr}}$ Triple Doppler lidar $\left(\mathrm{m} \mathrm{s}^{-1}\right)$

W Triple Doppler lidar $\left(\mathrm{m} \mathrm{s}^{-1}\right)$

Figure 6. Linear regression of the 3-D velocity components retrieved from the triple RHI scans with the lidar profilers V1 and V2, and the NW and SE sonic anemometers for virtual tower 1 and all the considered heights.

Table 8. Error analysis for the retrieval of the 3-D wind velocity from the triple RHI scans at virtual tower 2. Linear regression with wind measurements performed with the lidar profilers V1 and V2, and NW and SE sonic anemometers.

\begin{tabular}{lccc}
\hline Height $(\mathrm{m})$ & $U_{\text {in }} R^{2}$ (slope) & $U_{\text {tr }} R^{2}$ (slope) & $W R^{2}$ (slope) \\
\hline \multicolumn{4}{c}{ V1 lidar } \\
\hline 60 & $0.9422(1.0292)$ & $0.4781(0.4275)$ & $0.0058(0.0085)$ \\
All heights together & $0.9424(0.9902)$ & $0.5664(0.3814)$ & $0.0707(0.0503)$ \\
\hline \multicolumn{5}{c}{ V2 lidar } \\
\hline 60 & $0.941 .0105)$ & $0.5296(0.3999)$ & $0.0443(0.0304)$ \\
\hline 0 & $0.9209(0.9632)$ & $0.6126(0.3894)$ & $0.0298(0.0226)$ \\
\hline \multicolumn{5}{c}{$0.9151(0.9859)$} & $0.5917(0.4149)$ & $0.0262(0.0202)$ \\
\hline 50 & NW sonic anemometer & \\
\hline \multicolumn{5}{c}{ SE sonic anemometer } \\
\hline 50 & $0.9335(1.1121)$ & $0.3744(0.3698)$ & $-0.0024(0.0005)$ \\
\hline
\end{tabular}



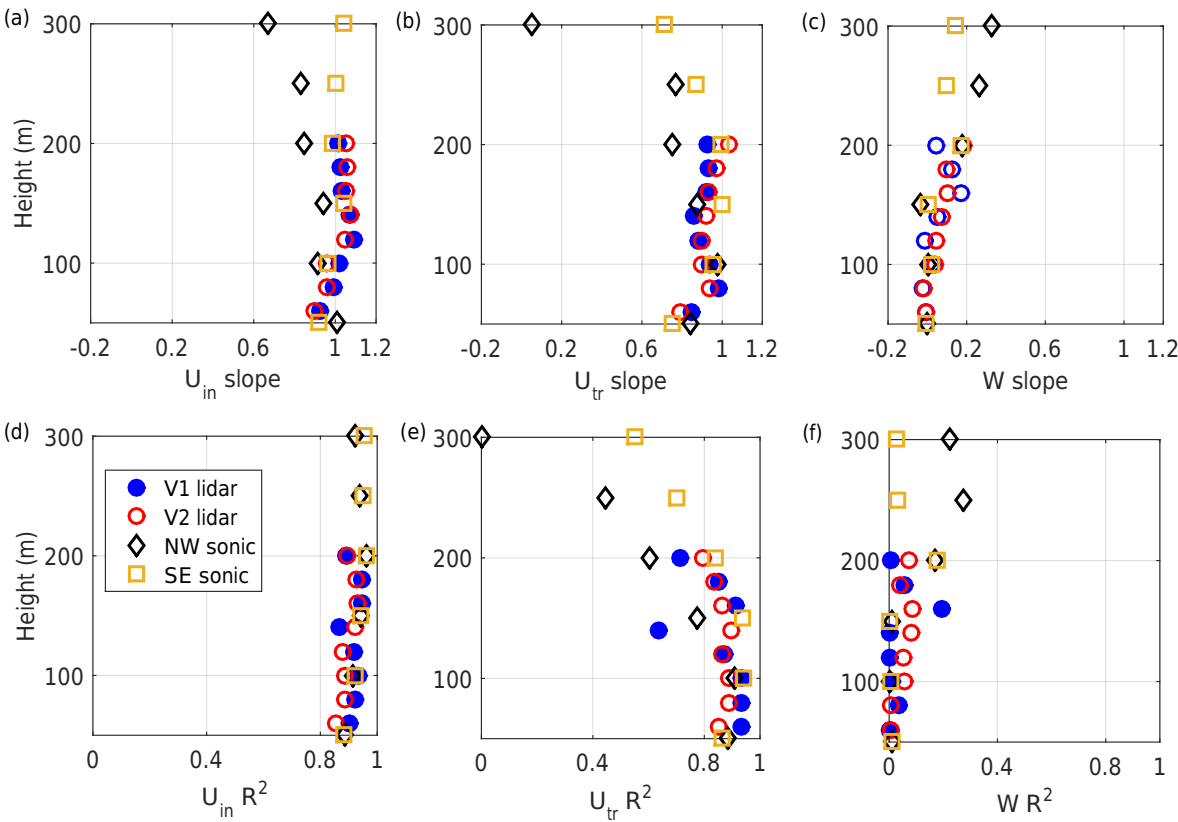

Figure 7. Linear regression of the 3-D velocity retrieved from the triple RHI scans for virtual tower 1 and compared with the lidar profilers V1 and V2, and the NW and SE sonic anemometers: (a) slope of the in-plane horizontal velocity, $U_{\text {in }}$; (b) slope of the transversal horizontal velocity, $U_{\mathrm{tr}}$; (c) slope of the vertical velocity, $W$; (d) $R^{2}$ value of the in-plane horizontal velocity, $U_{\text {in }}$; (e) $R^{2}$ value of the transversal horizontal velocity, $U_{\mathrm{tr}}$; (f) $R^{2}$ value of the vertical velocity, $W$.

and $R^{2}$ of 0.81 . The retrieval of the vertical velocity is very poor with an average slope of 0.03 and $R^{2}$ of 0.01 .

Histograms of the error in the retrieval of the 3-D velocity from the triple RHI scans, which are obtained by comparing the retrieved data with other instrument data, are reported in Fig. 8. In this figure, in addition to the typical error in the data retrieval, fixed bias errors are observed. Indeed, the error histograms are generally not symmetric but skewed towards either positive or negative values. These bias errors are typically smaller than $1 \mathrm{~m} \mathrm{~s}^{-1}$, but still noticeable. As mentioned above, the bias errors can also be a consequent of the relatively short sampling time and distance between virtual towers, the lidar profilers and the met tower.

Error statistics in the evaluation of the three velocity components from virtual tower 2 are reported in Table 8, which includes data for heights lower than $90 \mathrm{~m}$. Accuracy in the retrieval of the in-plane horizontal velocity, $U_{\text {in }}$, is very good and similar to that obtained for virtual tower 1 , while the retrieval of the vertical velocity, $W$, is very poor with an $R^{2}$ value approximately equal to 0 . A lower level of agreement is observed for the retrieval of the transversal horizontal velocity, $U_{\text {tr }}$, compared to the results related to virtual tower 1, with and average $R^{2}$ value of 0.57 and slope of 0.39 , which is due to the different elevation angles of the lidars, as reported in Table 5.

A strength of the triple RHI scans, compared to other multiple-lidar scanning techniques, is the capability of providing vertical profiles of the wind velocity field. By per- forming time averages over periods of about $10 \mathrm{~min}$, vertical profiles of the horizontal wind speed and direction can be obtained (Fig. 9a, b). For the horizontal wind velocity, generally good agreement is observed with the time-averaged velocity profiles obtained from the sonic anemometers installed on the BAO met tower. A slightly lower velocity is measured by the SE sonic anemometers, which is connected to possible wake effects produced by the met tower (McCaffrey et al., 2016). For the same reason, some differences are also observed for the wind direction estimated from the triple RHI scans and the one from the sonic anemometers. However, as reported in McCaffrey et al. (2016), a better estimate of the wind direction under wake conditions of the sonic anemometers is obtained by averaging the wind direction measured by the two sonic anemometers at a specific level. By considering this correction procedure, a better agreement between the wind direction estimate by the sonic anemometers and the triple RHI scan is achieved. A noticeable difference is observed with the profiling wind lidars. Regarding the wind direction, very good agreement is observed by comparing the wind data obtained from the sonic anemometers, especially for heights higher than $150 \mathrm{~m}$. By comparing the wind direction obtained from the triple RHI scans with that obtained from the lidar profilers V1 and V2, a bias error seems to be present between the different measurement techniques. Finally, errors of the mean velocity profiles evaluated as averages over the different heights are reported in Fig. $9 \mathrm{c}$ and d 

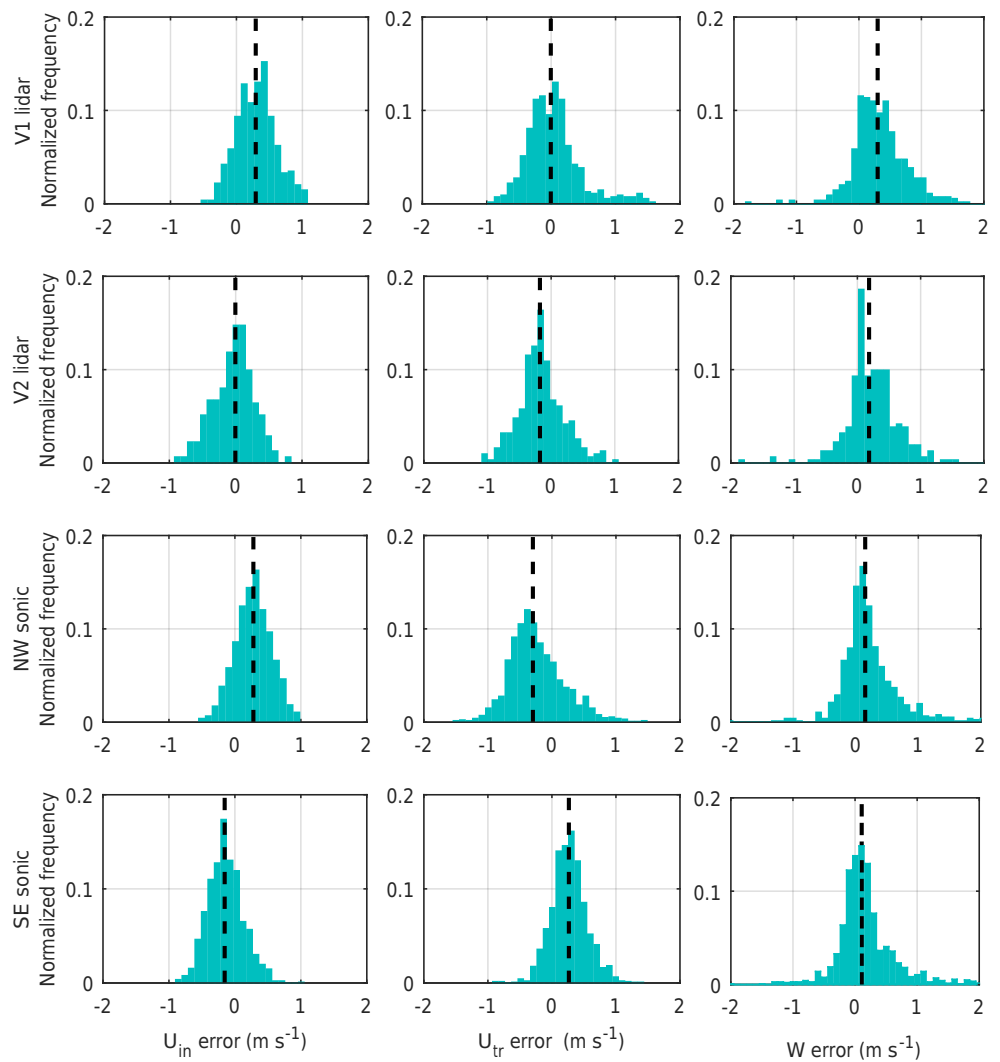

Figure 8. Histograms of the velocity difference in the retrieval of the 3-D wind velocity from triple RHI scans performed for virtual tower 1 and all the heights, which are obtained through comparison with measurements performed with the lidar profilers V1 and V2, and the NW and SE sonic anemometers. Columns represent different velocity components; rows represent different instruments. Median is reported with a vertical dashed black line.

for the horizontal velocity and wind direction, respectively. It is evident that errors are generally small.

\section{Conclusions}

Triple RHI scans were performed to retrieve vertical profiles of the 3-D wind velocity. This test is part of the XPIA experiment, which was funded by the US Department of Energy and was carried out at the Boulder Atmospheric Observatory in Erie, Colorado, for the period 2 March-31 May 2015. RHI scans were performed simultaneously with four scanning Doppler wind lidars in order to produce two virtual towers determined by the intersections of their vertical measurement planes. Assessment of the triple-Doppler data retrieval has been performed by comparing the triple RHI data with the wind velocity field measured from two lidar profilers and sonic anemometers installed over the $300 \mathrm{~m}$ tall met tower present on site.

Intercomparison of the triple RHI data with those obtained from the other instruments has shown that the proposed scanning strategy is highly compelling for producing vertical profiles of the horizontal wind velocity and wind direction. In- deed, very small errors (average correlation of 0.93 and slope of 1 for the horizontal velocity, and correlation of 0.8 and slope of 0.88 for the wind direction) are encountered, which are mainly related to the accuracy in the triple-lidar setup; relatively short sampling periods; and distance between the virtual towers, lidar profilers and the met tower. However, low-elevation triple RHI scans are generally not suitable for the characterization of the vertical velocity of the wind field. In case an accurate estimate of the vertical velocity is required, the triple RHI scan setup should be designed with one lidar measuring directly the vertical velocity. The other two lidars should have a shift of $90^{\circ}$ in the azimuthal angle and the smallest possible elevation angle according to the characteristics of the site and the carrier-to-noise ratio of the lidar signals.

\section{Data availability}

The data from all the instruments deployed during the XPIA field campaign are now available at DOE's Data Access Portal (DAP) located at https://a2e.pnnl.gov/data. Access to the general public has been open since 1 April 2016. In or- 

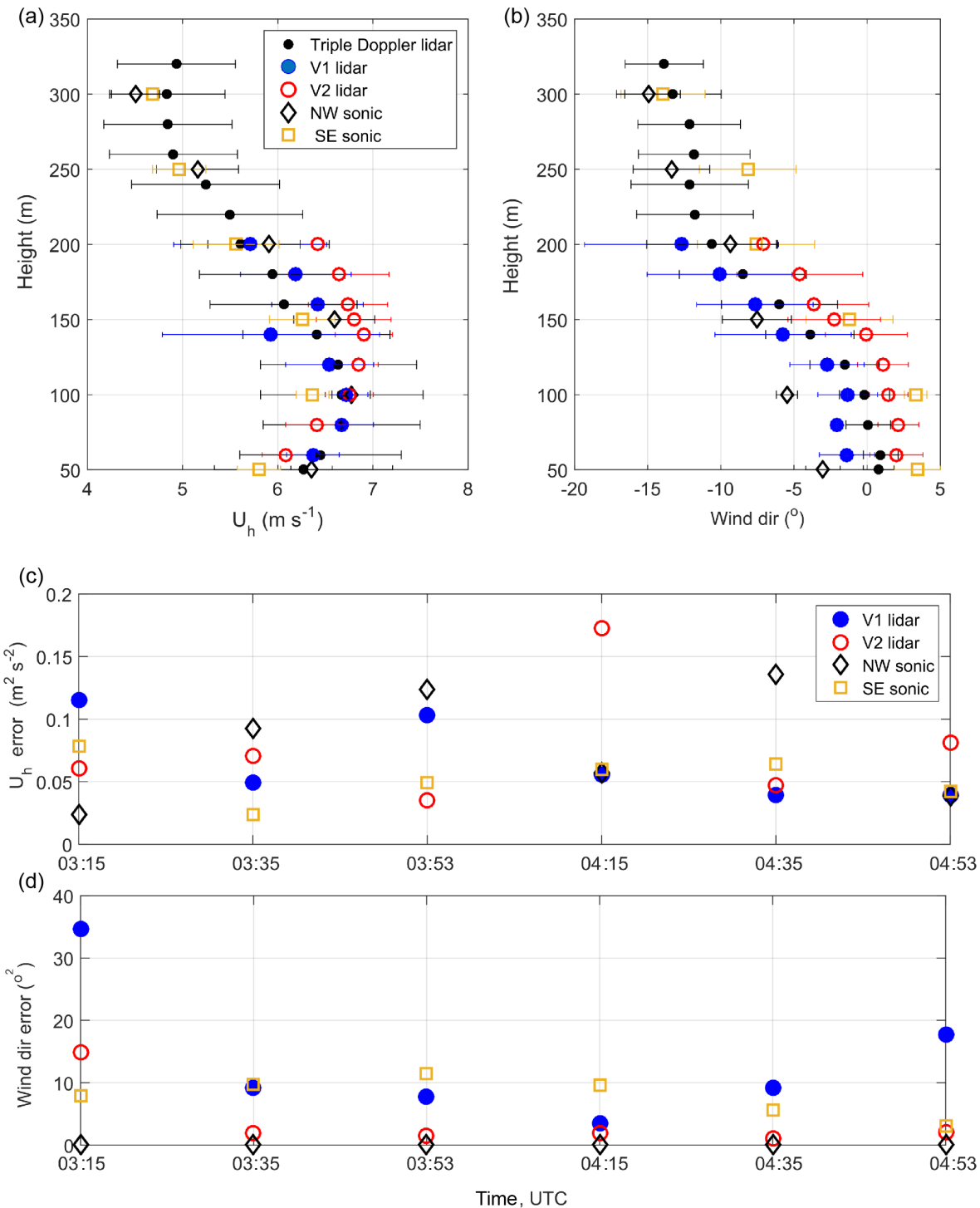

Figure 9. Time-averaged velocity profiles and error analysis: (a) average in-plane velocity, $U_{\mathrm{h}}$, for the time period 04:10-04:20 UTC; (b) average wind direction for the time period 04:10-04:20 UTC; (c) error in $U_{\mathrm{h}}$ for the different time-averaged vertical profiles; (d) error in wind direction for the different time-averaged vertical profiles.

der to access the data, users need to create an account on the website given above. For further inquiries please contact either Julie Lundquist (julie.lundquist@ colorado.edu) or James Wilczak (james.m.wilczak@noaa.gov).

Competing interests. The authors declare that they have no conflict of interest.

Acknowledgements. The authors acknowledge A. J. Clifton for his contribution to the XPIA experiment. This paper was developed based upon funding from the Alliance for Sustainable Energy, LLC, Managing and Operating Contractor for the National Renewable Energy Laboratory for the US Department of Energy.
Edited by: L. Bianco

Reviewed by: M. Courtney and three anonymous referees

\section{References}

Aitken, M., Rhodes, M., and Lundquist, J. K.: Performance of a wind-profiling lidar in the region of wind turbine rotor disks, J. Atmos. Ocean. Tech., 29, 347-355, 2012.

Aitken, M. L., Banta, R. M., Pichugina, Y. L., and Lundquist, J. K.: Quantifying wind turbine wake characteristics from scanning remote sensor data, J. Atmos. Ocean. Tech., 31, 765-787, 2014.

Banta, R. M., Newsom, R. K., Lundquist, J. K., Pichugina, Y. L., Coulter, R. L., and Mahrt, L.: Nocturnal low-level jet characteris- 
tics over Kansas during cases-99, Bound.-Layer Meteorol., 105, 221-252, 2002.

Banta, R. M., Pichughina, Y. L., Kelley, N. D., Hardesty, R. M., and Brewer, W. A.: Wind energy meteorology, B. Am. Meteorol. Soc., 94, 883-902, 2013.

Banta, R. M., Pichugina, Y. L., Brewer, W. A., Lundquist, J. K., Kelley, N. D., Sandberg, S. P., Alvarez, R. J., Hardesty, R. M., and Weickmann, A. M.: 3D volumetric analysis of wind turbine wake properties in the atmosphere using high-resolution Doppler lidar, J. Atmos. Ocean. Tech., 32, 904-914, 2015.

Barthelmie, R. J., Pryor, S. C., Frandsen, S. T., Hansen, K. S., Schepers, J. G., Rados, K., Schlez, W., Neubert, A., Jensen, L. E., and Neckelmann, S.: Quantifying the impact of wind turbine wakes on power output at offshore wind farms, J. Atmos. Ocean. Tech., 27, 1302-1317, 2010.

Berg, J., Vasiljevic, N., Kelly, M., Lea, G., and Courtney, M.: Addressing spatial variability of surface-layer wind with long-range windscanners, J. Atmos. Ocean. Tech., 32, 518-527, 2015.

Bingöl, F., Mann, J., and Foussekis, D.: Conically scanning lidar error in complex terrain, Meteor. Z., 18, 189-195, 2009.

Bonin, T. A., Blumberg, W. G., Klein, P. M., and Chilson, P. B.: Thermodynamic and turbulence characteristics of the southern great plains nocturnal boundary layer under differing turbulent regimes, Bound.-Layer Meteorol., 157, 401-420, 2015.

Calhoun, R., Heap, R., Princevac, M., Newsom, R., Fernando, H., and Ligont, D.: Virtual towers using coherent Doppler lidar during the joint urban 2003 dispersion experiment, J. Appl. Meteorol. Clim., 45, 1116-1126, 2006.

Carbajo-Fuertes, F., Iungo, G. V., and Porté-Agel, F.: 3D turbulence measurements using three synchronous wind lidars: validation against sonic anemometry, J. Atmos. Ocean. Tech., 31, 15491556, 2014

Cherukuru, N. W., Calhoun, R., Lehner, M., Hoch, S. W., and Whiteman, C. D.: Instrument configuration for dual-Doppler lidar coplanar scans: METCRAX II, J. Appl. Remote Sens., 9, 096090-096090, 2015.

Courtney, M., Wagner, R., and Lindelöw, P.: Testing and comparison of lidars for profile and turbulence measurements in wind energy, IOP Conf. Ser., Earth Environ. Sci., 1, 012021, doi:10.1088/1755-1307/1/1/012021, 2008.

Emeis, S., Harris, M., and Banta, R. M.: Boundary-layer anemometry by optical remote sensing for wind energy applications, Meteor. Z., 16, 337-347, 2007.

George, R. and Yang, J.: A survey for methods of detecting aircraft vortices, Chicago, IL, 2012, in: Proc. ASME Int. Design Eng. Tech. Conf. Comp. Infor. Eng., Chicago, IL, 41-50, 2012.

Hill, M., R. Calhoun, H. J. S. F., Wieser, A., Dornbrack, A., Weissmann, M., Mayr, G., and Newsom, R.: Coplanar Doppler lidar retrieval of rotors from T-REX, J. Atmos. Sci., 67, 713-729, 2010.

Horanyi, A., Cardinali, C., and Rennie, M.: The assimilation of horizontal line-of-sight wind information into the ECMWF data assimilation and forecasting system. Part I: the assessment of wind impact, Q. J. Roy, Meteor. Soc., 141, 1223-1232, 2015.

Iungo, G. V.: Experimental characterization of wind turbine wakes: wind tunnel tests and wind LiDAR measurements, J. Wind Eng. Ind. Aerodyn., 149, 35-39, 2016.

Iungo, G. V. and Porté-Agel, F.: Measurement procedures for characterization of wind turbine wakes with scanning Doppler wind LiDARs, Adv. Sci. Res., 10, 71-75, 2013 b.
Iungo, G. V. and Porté-Agel, F.: Volumetric lidar scanning of wind turbine wakes under convective and neutral atmospheric stability regimes, J. Atmos. Ocean. Tech., 31, 2035-2048, 2014.

Iungo, G. V., Wu, Y.-T., and Porté-Agel, F.: Field measurements of wind turbine wakes with lidars, J. Atmos. Ocean. Tech., 30, 274 287, 2013a.

Jakobsen, J. B., Cheynet, E., Snæbjörnsson, J., Mikkelsen, T., Sjöholm, M., Angelou, N., Hansen, P., Mann, J., Svardal, B., Kumer, V., and Reuder, J.: Assessment of wind conditions at a fjord inlet by complementary use of sonic anemometers and LiDARs, 12th Deep Sea Offshore Wind R \& D Conf., EERA DeepWind, 80, 411-421, 2015.

Kaimal, J. C. and Gaynor, J. E.: The Boulder Atmospheric Observatory, J. Clim. Appl. Meteorol., 22, 863-880, 1983.

Käsler, Y., Rahm, R., Simmet, R., and Kuhn, M.: Wake measurements of a multi-MW wind turbine with coherent long-range pulsed Doppler wind lidar, J. Atmos. Ocean. Tech., 27, 15291532, 2010.

Lundquist, J. K., Churchfield, M. J., Lee, S., and Clifton, A.: Quantifying error of lidar and sodar Doppler beam swinging measurements of wind turbine wakes using computational fluid dynamics, Atmos. Meas. Tech., 8, 907-920, doi:10.5194/amt-8-9072015, 2015.

Lundquist, J. K., Wilczak, J. M., Ashton, R., Bianco, L., Brewer, W. A., Choukulkar, A., Clifton, A. J., Debnath, M., Delgado, R., Friedrich, K., Gunter, S., Hamidi, A., Iungo, G. V., Kaushik, A., Kosovic, B., Langan, P., Lass, A., Lavin, E., Lee, J. C.-Y., McCaffrey, K. L., Newsom, R. K., Noone, D. C., Oncley, S. P., Quelet, P. T., Sandberg, S. P., Schroeder, J. L., Shaw, W. J., Sparling, L., Martin, C. S., Pe, A. S., Strobach, E., Tay, K., Vanderwende, B. J., Weickmann, A., Wolfe, D., and Worsnop, R.: The eXperimental Planetary boundary layer Instrument Assessment (XPIA), tech. rep. number pending, US Department of Energy, 2016a.

Lundquist, J. K., Wilczak, J. M., Ashton, R., Bianco, L., Brewer, W. A., Choukulkar, A., Clifton, A. J., Debnath, M., Delgado, R., Friedrich, K., Gunter, S., Hamidi, A., Iungo, G. V., Kaushik, A., Kosović, B., Langan, P., Lass, A., Lavin, E., Lee, J. C.-Y., McCaffrey, K. L., Newsom, R. K., Noone, D. C., Oncley, S. P., Quelet, P. T., Sandberg, S. P., Schroeder, J. L., Shaw, W. J., Sparling, L., Martin, C. S., Pe, A. S., Strobach, E., Tay, K., Vanderwende, B. J., Weickmann, A., Wolfe, D., and Worsnop, R.: Assessing state-of-the-art capabilities for probing the atmospheric boundary layer: the XPIA field campaign, B. Am. Meteorol. Soc., doi:10.1175/BAMS-D-15-00151.1, 2016b.

Machefaux, E., Larsen, G. C., Troldborg, N., Gaunaa, M., and Rettenmeier, A.: Empirical modeling of single-wake advection and expansion using full-scale pulsed lidar-based measurements, Wind Energy, 18, 2085-2103, 2015.

Mann, J., Cariou, J.-P., Courtney, M. S., Parmantier, R., Mikkelsen, T., Wagner, R., Lindelow, P., Sjoholm, M., and Enevoldsen, K.: Comparison of $3 \mathrm{D}$ turbulence measurements using three staring wind lidars and a sonic anemometer, Meteorol. Z., 18, 135-140, 2009.

McCaffrey, K., Quelet, P., Choukulkar, A., Wilczak, J. M., Wolfe, D. E., Oncley, S., Brewer, A., Debnath, M., Ashton, R., Iungo, G. V., and Lundquist, J. K.: Identification of Tower Wake Distortions Using Sonic Anemometer and Lidar Measurements, At- 
mos. Meas. Tech. Discuss., doi:10.5194/amt-2016-179, in review, 2016.

Mikkelsen, T., Courtney, M., Antoniou, I., and Mann, J.: Wind scanner: a full-scale laser facility for wind and turbulence measurements around large wind turbines, in: Europ. Wind Energy Conf., Brussels, 012018, 2008.

Newsom, R. K., Berg, L. K., Shaw, W. J., and Fischer, L.: Turbinescale wind field measurements using dual-Doppler lidar, Wind Energy, 18, 219-235, 2015.

Rhodes, M. E. and Lundquist, J. K.: The effect of wind-turbine wakes on summertime US midwest atmospheric wind profiles as observed with ground-based Doppler lidar, Bound.-Layer Meteorol., 149, 85-103, 2013.

Sathe, A. and Mann, J.: A review of turbulence measurements using ground-based wind lidars, Atmos. Meas. Tech., 6, 3147-3167, doi:10.5194/amt-6-3147-2013, 2013.

Schepers, J., Obdam, J., and Prospathopoulos, J.: Analysis of wake measurements from the ECN wind turbine test site Wieringermeer, EWTW, Wind Energy, 15, 575-591, 2012.
Simley, E., Angelou, N., Mikkelsen, T., Sjöholm, M., Mann, J., and Pao, L. Y.: Characterization of wind velocities in the upstream induction zone of a wind turbine using scanning continuous-wave lidars, J. Renew. Sustain. Energ., 8, 013301, doi:10.1063/1.4940025, 2016

Smalikho, I. N. and Banakh, V. A.: Estimation of aircraft wake vortex parameters from data measured with a $1.5-\mu \mathrm{m}$ coherent Doppler lidar, Opt. Lett., 40, 3408-3411, 2015.

Smalikho, I. N., Banakh, V. A., Pichugina, Y. L., Brewer, A. L., Banta, R. M., Lundquist, J. K., and Kelley, N. D.: Lidar investigation of atmosphere effect on a wind turbine wake, J. Atmos. Ocean. Tech., 30, 2554-2570, 2013.

Vanderwende, B. J., Lundquist, J. K., Rhodes, M. E., Takle, E. S., and Irvin, S. L.: Observing and simulating the summertime lowlevel jet in central Iowa, Mon. Weather Rev., 143, 2319-2336, 2015.

Wilczak, J. M., Oncley, S. P., and Stage, S. A.: Sonic anemometer tilt correction algorithms, Bound.-Layer Meteorol., 99, 127-150, 2001. 